\title{
Parental intention to have daughters receive the human papillomavirus vaccine
}

\author{
Gina S. Ogilvie MD MSc, Valencia P. Remple PhD, Fawziah Marra PharmD, Shelly A. McNeil MD, \\ Monika Naus MD MHSc, Karen L. Pielak MSN, Thomas G. Ehlen MD, Simon R. Dobson MD, \\ Deborah M. Money MD, David M. Patrick MD MHSc
}

\section{ABSTRACT}

Background: Concerns have been raised that parents may be reluctant to have their daughters receive the human papillomavirus (HPV) vaccine, because of a belief that doing so might be interpreted as condoning earlier and more frequent sexual activity. We determined intentions regarding vaccination among Canadian parents and factors that predicted parental intention to have their daughters vaccinated against HPV.

Methods: Parents of children 8-18 years of age, recruited from across Canada, were asked to respond to questions in the context of a grade 6 , publicly funded, school-based HPV vaccine program. We performed backward logistic regression analysis to identify factors predictive of parents' intention to have their daughters vaccinated against HPV.

Results: Of the 1350 respondents with female children, more than $70 \%(73.8 \%$; $95 \%$ confidence interval $[\mathrm{Cl}] 71.5 \%-$ $76.1 \%$ ) intended to have their daughters undergo vaccination against HPV. In multivariable modelling, parents who had positive attitudes toward vaccines (odds ratio [OR] 9.9, $95 \% \mathrm{Cl}$ 4.7-21.1), those who were influenced by subjective norms (OR 9.2, 95\% Cl 6.6-12.9), those who felt that the vaccine had limited influence on sexual behaviour (OR 3.2, $95 \% \mathrm{Cl}$ 2.2-4.6) and those who thought someone they knew was likely to get cervical cancer (OR 1.5, 95\% Cl 1.1-2.1) were more likely to intend that their daughters receive the HPV vaccine. Parents who were older (v. younger) (OR 0.6, 95\% $\mathrm{Cl} 0.4-0.8)$ and those who resided in British Columbia or Yukon Territory (v. Atlantic Canada) (OR 0.5, 95\% Cl 0.3-0.9) were less likely to intend that their daughters receive the HPV vaccine.

Interpretation: Most of the parents surveyed intended that their daughters would receive vaccination against HPV. Overall attitudes toward vaccines in general and toward the HPV vaccine in particular constituted the most significant predictor of parental intention with regard to vaccination.

Une version française de ce résumé est disponible à l'adresse www.cmaj.ca/cgi/content/full/I77/I2/I506/DCI

CMAJ 2007;177(12):1506-12
$\mathrm{T}$ he vaccine against the human papillomavirus (HPV) represents a major step toward the prevention of cervical cancer. ${ }^{1,2} \mathrm{HPV}$ is a sexually acquired virus, and mathematical modelling and economic analyses have demonstrated that the vaccine's maximum benefit in terms of preventing cervical cancer is achieved when vaccination programs target female and possibly male adolescents before their sexual debut, likely before the age of $\mathrm{I} 2$ years. ${ }^{3}$ The clinical efficacy and safety of the currently available HPV vaccine have been established, ${ }^{4}$ but concerns have been raised that parents may be reluctant to have their children undergo vaccination at this age, because of a belief that doing so might be interpreted to mean that they are condoning or even promoting earlier and more frequent sexual activity. Since parental attitudes play a crucial role in vaccination uptake and can provide direction for messaging and education in support of vaccination uptake, ${ }^{5}$ we sought to determine parental intentions to have daughters vaccinated against HPV and the factors that predict those intentions.

\section{Methods}

\section{Recruitment}

Invited participants were men and women at least I9 years of age who were parents or guardians of children between 8 and I8 years of age and who could respond to questions in English or French. The participants were recruited from across Canada between June 2006 and March 2007 by random-digit dialling. Respondents were offered an opportunity to participate in a draw for a gift.

\section{Development of survey tool}

The survey was based on the theory of planned behaviour. ${ }^{6}$ In brief, this psychological model of behaviour change parses out the elements that contribute to an actual behaviour or the most proximate measure of behaviour change, known as be-

From the University of British Columbia (Ogilvie, Remple, Marra, Naus, Ehlen, Dobson, Money, Patrick), Vancouver, BC; the Canadian Centre for Vaccinology (McNeil), Dalhousie University, Halifax, NS; the British Columbia Centre for Disease Control (Ogilvie, Naus, Pielak, Patrick), Vancouver, BC; and the Women's Health Research Institute (Money), Provincial Health Services Authority, Vancouver, BC 
haviour intention. The survey tool was developed inductively, with content created through an extensive literature search exploring factors that affect vaccine-related behaviour ${ }^{4,7-9}$ and through an elicitation survey of Io parents to determine the key beliefs and attitudes related to their intention to have a child vaccinated against HPV. A focus group of to parents pilot-tested a draft version of the survey, providing feedback on its content, their comprehension and domains of relevance. The final survey was translated into French, and the translation was verified by having the French version backtranslated into English; no significant errors were noted.

For each participant, the following demographic characteristics were assessed: age and sex of the respondent; region of residence; number of children and their sex and age; respondent's education, cultural background and religious affiliation; and household composition (e.g., I- or 2-parent household). At the start of the survey, each participant was asked about adherence to recommended vaccination schedules for his or her children, about knowledge of cervical cancer and HPV, and about the likelihood that someone the participant knows will get cervical cancer (assessed by means of a 7-point Likert scale, where $\mathrm{I}=$ strongly disagree, $4=$ neutral and $7=$ strongly agree). One of several trained research interviewers then read a standardized script, providing the participant with information about HPV, the HPV vaccine, the role of HPV in cervical cancer, the nature of HPV transmission and the efficacy of the HPV vaccine. The vaccine description did not use proprietary names, was not product specific and referred to the efficacy of the vaccine against HPV related to cervical cancer and not HPV related to genital warts. The participant was next asked to respond to a series of questions in the context of a grade 6 (students II-I2 years of age), publicly funded, school-based HPV vaccination program, including a question about the intention to have his or her daughter receive the HPV vaccine. The participant was also asked about 4 specific psychological constructs that could predict an intention to vaccinate: attitudes toward vaccines in general and toward the HPV vaccine in particular, subjective norms about HPV vaccination (perceptions of others' recommendations about whether one should have a daughter undergo vaccination), perceived behavioural control over HPV vaccination (perceptions about the relative ease or difficulty of having a daughter vaccinated against HPV) and attitudes toward the influence of HPV vaccination on the sexual behaviour of adolescents. For each construct, 2-6 items were assessed by means of a 7-point Likert scale, as described earlier.

The study received ethics approval from the Behavioural Research Ethics Board at the University of British Columbia.

\section{Sample size}

Previous studies have reported that $70 \%$ of parents intend to have their children vaccinated against HPV. ${ }^{7-9}$ To generate a national estimate of parental intention with a $95 \%$ confidence interval of $\pm 3 \%$, at least 896 participants were needed.

\section{Analysis}

We conducted descriptive analyses of demographic characteristics. We calculated mean values for the psychological construct scales and established item reliability for the scales us- ing Cronbach's $\alpha$, values of at least 0.6 indicating acceptable internal consistency. For scale items, aggregated scores were dichotomized, with a mean value of 4.5 as a cutoff and scores of 4.5 or greater indicating a generally positive value (i.e., a positive attitude, perception of behavioural control or subjective norm). We conducted bivariate analyses to compare the responses of parents who intended to have their daughters vaccinated against HPV with those of parents who did not intend to do so. For these remaining analyses, we defined intention to vaccinate as a response of 5 or greater on the Likert scale to the statement "I intend to have my daughter(s) receive the HPV vaccine (once it becomes available)." Respondents who did not agree with this statement or gave a neutral response were coded as not intending to vaccinate. We included variables that achieved $p<0.05$ in a multivariable model to achieve a best-fit model. We performed backward logistic regression analysis to calculate adjusted odds ratios (ORs) to identify the factors predictive of parents' intention to have their daughters vaccinated against HPV.

\section{Results}

Between June 2006 and March 2007, calls were made to a total of 32834 in-service telephones across Canada. Of the 23969 homes where an answer was obtained within 4 calls, 3979 had eligible candidates, of whom $2 \operatorname{IO} 9$ (53.0\%) consented to participate and 2083 completed the survey. About three-quarters of the respondents were female, and most had no more than 3 children; about half had heard of HPV but only one-quarter knew that the virus is transmitted through sexual contact (Table I). Of the $1350(64.8 \%)$ respondents with one or more female children, $73.8 \%$ (95\% CI $7 \mathrm{I} .5 \%-76 . \mathrm{I} \%$ ) reported that they intended to have their daughters vaccinated against HPV. In different regions of the country, the intention to vaccinate varied, from a low of $62.8 \%$ ( $95 \%$ CI 60.2-65.4) in British Columbia and Yukon Territory to a high of $82.6 \%$ (95\% CI 8o.6-84.6) in Atlantic Canada ( $p<0.01$ ) (Table 2).

The internal reliability of the psychological constructs was acceptable (Cronbach's $\alpha \geq 0.6$ ) for the 3 constructs and limited for perceived behavioural control (Table 3). In the bivariate analysis, we found that the intention to vaccinate was associated with age, sex and region of residence of the respondent, household composition, uptake of childhood vaccination, awareness and knowledge of HPV, belief that someone the respondent knew would get cervical cancer, overall attitudes toward vaccines and the HPV vaccine, subjective norms, perceived behavioural control of the decision to vaccinate and perceived influence of vaccination on sexual behaviour (Table 4). Cultural background, education, religious affiliation and role of religious beliefs in daily decisions were not associated with intention to vaccinate. In addition to the variables that were significant in bivariate modelling, we included the role of religion in daily decisions in the multivariable modelling, given perceptions that this variable would have an important role in decision-making related to the HPV vaccine. ${ }^{10,11}$ In the multivariable modelling, we found that parents who had positive attitudes toward vaccines in general and the HPV vaccine in particular, those who were influenced by subjective norms, 
those who felt that the vaccine had limited influence on sexual behaviour, those who believed that someone they knew would get cervical cancer, those who were younger, and those residing in Atlantic Canada (v. British Columbia or the Yukon Territory) were significantly more likely to intend that their daughters undergo HPV vaccination (Table 4).

\section{Interpretation}

More than $70 \%$ of the parents of girls between the ages of 8 and I8 years who were surveyed in this national study indicated an intention to have their daughters receive the HPV vaccine in school-based, publicly funded vaccination programs for girls II and I2 years of age. This estimate, although consistent with published international estimates, ${ }^{7,9,11-14}$ is probably conservative, because parents who reported that they were "neutral" on the issue of having their daughters receive the vaccine were coded in our analysis as not intending to vaccinate. The strongest predictor of parental intention to vaccinate was parental attitudes toward vaccines in general and toward the HPV vaccine in particular. Recommendations in favour of HPV vaccination from health care professionals (physicians in particular), family and friends, and community leaders also constituted an important predictor of parental in-

Table 1: Baseline characteristics, knowledge and attitudes of study participants $(n=2083)$

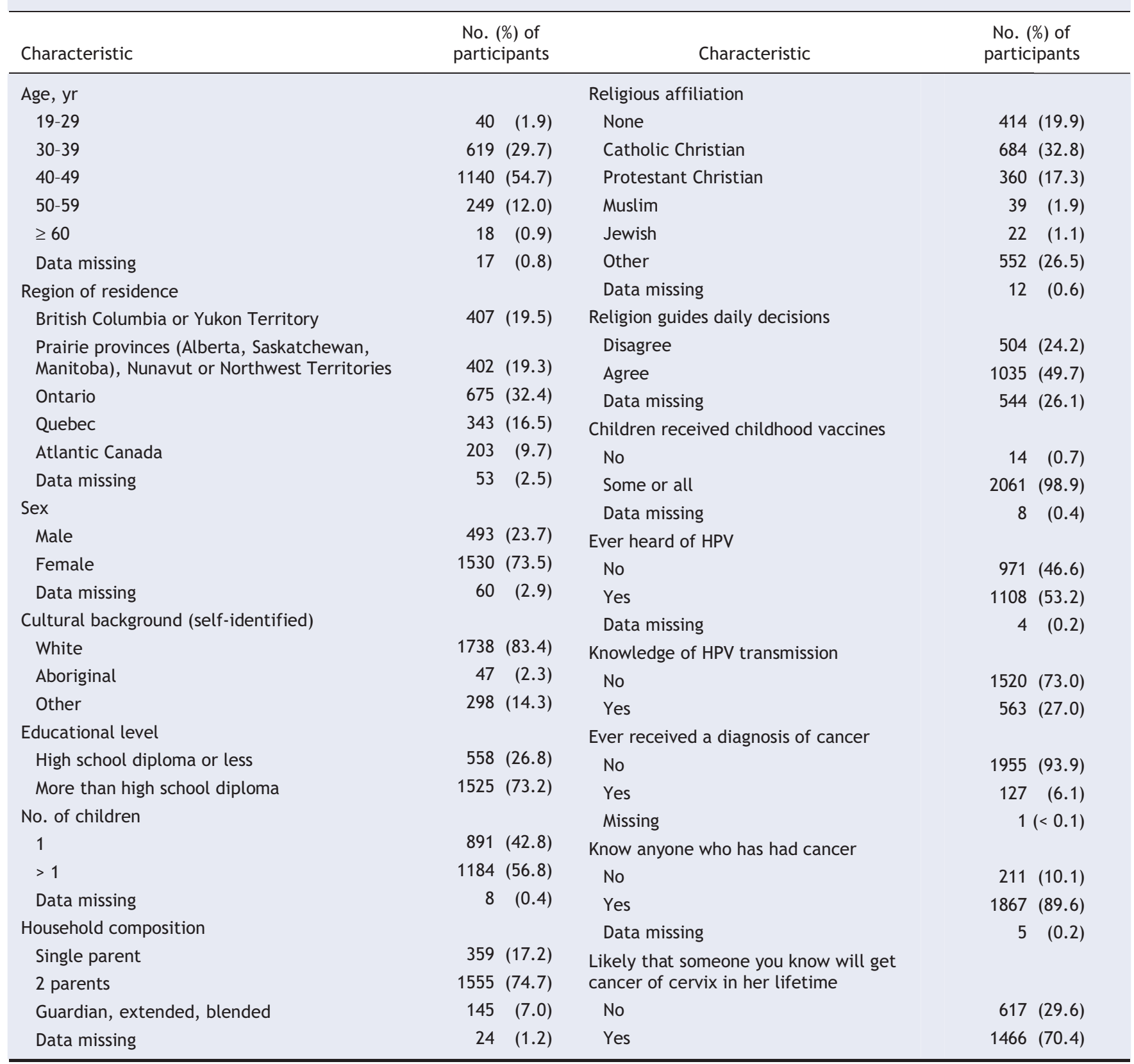

Note: HPV = human papillomavirus. 
Table 2: Regional representation and crude estimates of parental intention to have daughters receive HPV vaccine

\begin{tabular}{lccc}
\hline Region of Canada & \% of sample (no.) & \% of population* & $\begin{array}{c}\text { Parental intention to have daughters } \\
\text { receive HPV vaccine (95\% Cl) } \dagger\end{array}$ \\
\hline $\begin{array}{l}\text { British Columbia or Yukon Territory } \\
\text { Prairie provinces, Nunavut or }\end{array}$ & $19.5(407)$ & 13.3 & $62.8(60.2-65.4)$ \\
Northwest Territories & $19.3(402)$ & 17.0 & $77.4(75.2-79.6)$ \\
Ontario & $32.4(675)$ & 38.9 & $75.3(73.0-77.6)$ \\
Quebec & $16.5(343)$ & 23.5 & $77.5(75.3-79.7)$ \\
Atlantic Canada & $9.7(203)$ & 7.3 & $82.6(80.6-84.6)$ \\
\hline Overall & & & $73.8(71.5-76.1)$ \\
\hline
\end{tabular}

Note: $\mathrm{HPV}=$ human papillomavirus, $\mathrm{Cl}=$ confidence interval.

*According to data from Statistics Canada for 2005. ${ }^{17}$

†Estimates and $95 \% \mathrm{Cls}$ are based on responses from the 1350 participants who had female offspring.

Table 3: Results of psychological construct scales

\begin{tabular}{|c|c|c|}
\hline Attitude or norm & Mean score* $(\mathrm{SD})$ & Cronbach's $\alpha \dagger$ \\
\hline \multicolumn{3}{|l|}{$\begin{array}{l}\text { Attitudes toward vaccines in general and the HPV vaccine in particular } \\
(n=2021)\end{array}$} \\
\hline Childhood vaccines are beneficial & $6.2(1.1)$ & \\
\hline HPV vaccine is beneficial for girls & $6.0(1.3)$ & \\
\hline HPV vaccine is beneficial for boys & $5.8(1.4)$ & \\
\hline Cervical cancer is a serious illness & $6.7(0.7)$ & \\
\hline HPV vaccine is effective in preventing cervical cancer & $5.4(1.2)$ & \\
\hline HPV vaccine is safe & $4.6(1.1)$ & \\
\hline Overall & $5.8(0.8)$ & 0.8 \\
\hline \multicolumn{3}{|l|}{ Subjective norms $(n=1546)$} \\
\hline Physician's recommendation to vaccinate is influential & $6.2(1.4)$ & \\
\hline Public health nurse's recommendation to vaccinate is influential & $5.7(1.6)$ & \\
\hline Recommendations of friends or family to vaccinate are influential & $4.8(1.7)$ & \\
\hline Teacher's or principal's recommendation to vaccinate is influential & $4.6(1.7)$ & \\
\hline Spiritual leader's recommendation to vaccinate is influential & $4.1(1.9)$ & \\
\hline Overall & $5.1(1.4)$ & 0.9 \\
\hline \multicolumn{3}{|l|}{ Direct perceived behavioural control $(n=2072)$} \\
\hline $\begin{array}{l}\text { Respondent is confident that he or she could have children receive } \\
\text { vaccine }\end{array}$ & $6.0(1.1)$ & \\
\hline Decision to have child undergo vaccination is within parent's control & $5.8(1.7)$ & \\
\hline Overall & $5.9(1.1)$ & 0.3 \\
\hline \multicolumn{3}{|l|}{ Attitudes toward influence of HPV vaccine on sexual behaviour $(n=2062)$} \\
\hline Important that children be vaccinated against HPV before sexual debut & $5.9(1.4)$ & \\
\hline HPV vaccine will not make children sexually active at an earlier age & $5.8(1.6)$ & \\
\hline $\begin{array}{l}\text { Adolescents who receive the HPV vaccine will not be encouraged } \\
\text { to engage in unsafe sex }\end{array}$ & $5.5(1.7)$ & \\
\hline $\begin{array}{l}\text { Adolescents who receive HPV vaccine will not have a higher number } \\
\text { of sexual partners }\end{array}$ & $5.7(1.5)$ & \\
\hline Adolescents who practise safe sex will avoid HPV acquisition & $4.2(1.9)$ & \\
\hline Overall & $5.4(1.0)$ & 0.6 \\
\hline
\end{tabular}

Note: $\mathrm{HPV}=$ human papillomavirus, SD = standard deviation

*Responses relate to a 7-point Likert scale.

tltem reliability for the psychological construct scales was established by means of Cronbach's $\alpha$, where a value of at least 0.6 indicates acceptable internal consistency. 
tention to vaccinate. In contrast, cultural background, education, religious affiliation and role of religious beliefs in daily decisions, all of which might be expected to influence such decisions, were not associated with parental intention to vaccinate.

Just over $20 \%$ of the parents of girls (285/1350) expressed concerns about the influence of the HPV vaccine on sexual behaviour. Along with parental age, such concerns represented a significant predictor of the intention to vaccinate. This finding may be related to different attitudes among younger versus older parents regarding the implications of sexual health initiatives on the sexual behaviours of youth. Parents need reassurance that sexual health initiatives and receipt of a vaccine for a sexually acquired virus that causes cancer is unlikely to promote unsafe sexual activity. ${ }^{15,16}$
Intention to vaccinate varies by region, from about $63 \%$ in British Columbia or the Yukon Territory to over $80 \%$ in Atlantic Canada (Table 2). ${ }^{17}$ Regional variations in vaccination rates are not unusual, ${ }^{18,19}$ although childhood vaccination rates in British Columbia are comparable to those in other provinces where such assessments are conducted. These findings could be due in part to the dynamic backdrop of the marketing of the HPV vaccine Gardasil (Merck) in North America in the past year. ${ }^{20}$ However, our analysis did not reveal any significant difference in intention to vaccinate with the HPV vaccine between parents recruited in the first half of the study and those recruited in the latter half (data not shown), and knowledge of HPV was included in the multivariable modelling. Further assessment is required to understand the reasons underpinning the difference in parental at-

Table 4: Bivariate and multivariable analysis of predictors of intention to have daughters receive the HPV vaccine (part 1)

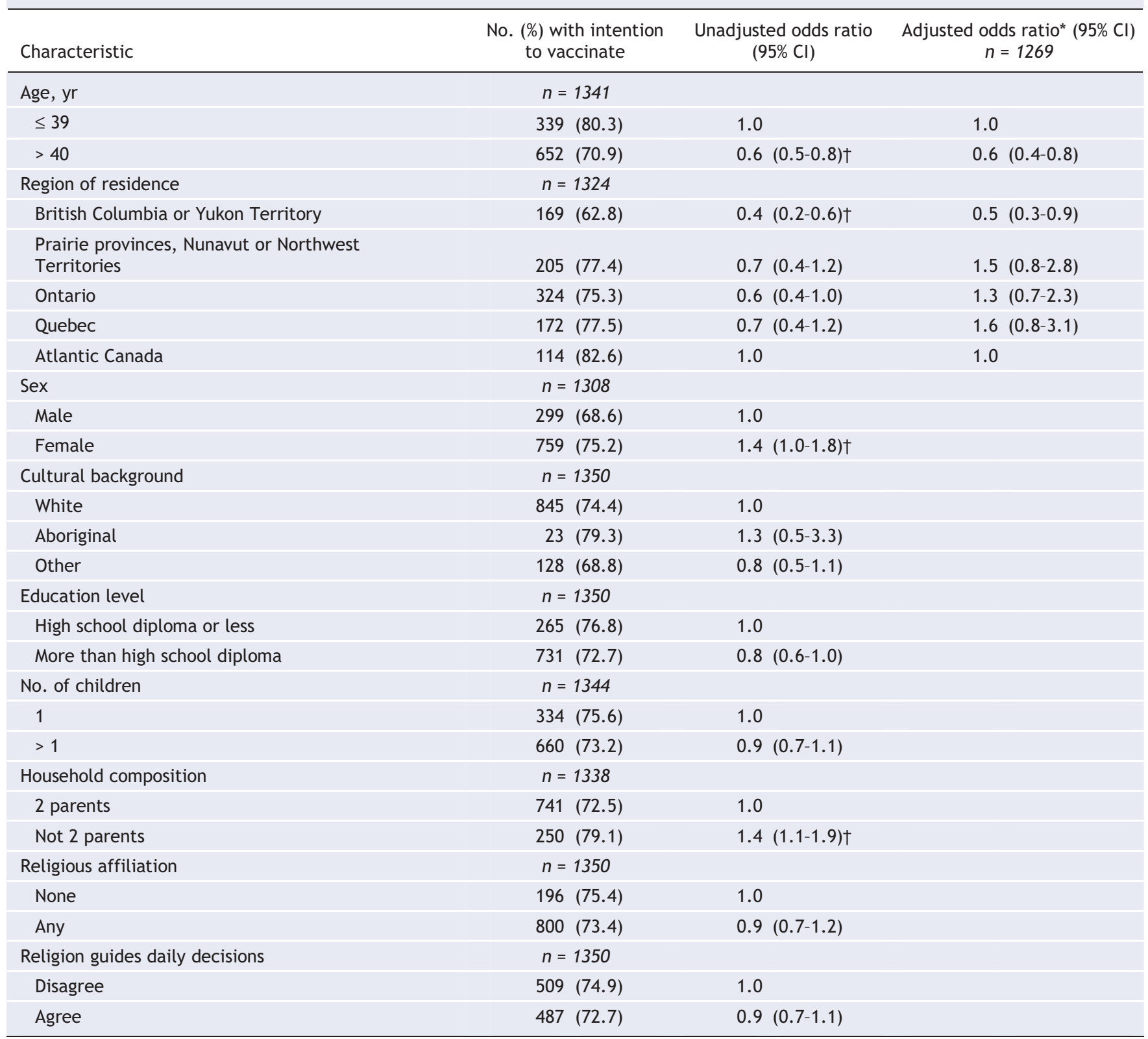


titudes toward the HPV vaccine in British Columbia and the Yukon Territory compared with Atlantic Canada.

There were some limitations to our study. We used a random-digit dialling method, which can result in a recruitment bias toward more educated individual $\mathrm{s}^{21}$ and may underrecruit participants from rural or remote regions. In addition, the response rate (about 55\%) was slightly less than that reported by others; however, given the large sample size in our study, this likely does not represent a threat to the validity of the findings. The internal consistency of one scale item, perceived behavioural control, was poor (Cronbach's $\alpha=0.3$ ) (Table 3). However, this scale just achieved significance in the bivariate analysis and was not significant in the multivariable modelling. In contrast, the scales that were highly significant in the multivariable modelling were also highly internally con- sistent. In addition, there was overrepresentation of respondents from some regions (Atlantic Canada, Prairie provinces, and British Columbia or the Yukon Territory) and underrepresentation of respondents from the other regions, relative to their representation in the national population (Table 2). Regardless, given the relatively narrow confidence intervals for the estimates of intended vaccination uptake in these regions, our study provides precise estimates of intended vaccination rates in these areas. Despite these limitations, our findings are consistent with existing international literature, including our observation that most parents intend to have their daughters receive the HPV vaccine ${ }^{13}$ and our findings as to key predictors of intention to vaccinate. ${ }^{11,12,14,22,23}$

The HPV vaccine is an important element in efforts to prevent cervical cancer in Canada. Recent funding announce-

Table 4: Bivariate and multivariable analysis of predictors of intention to have daughters receive the HPV vaccine (part 2)

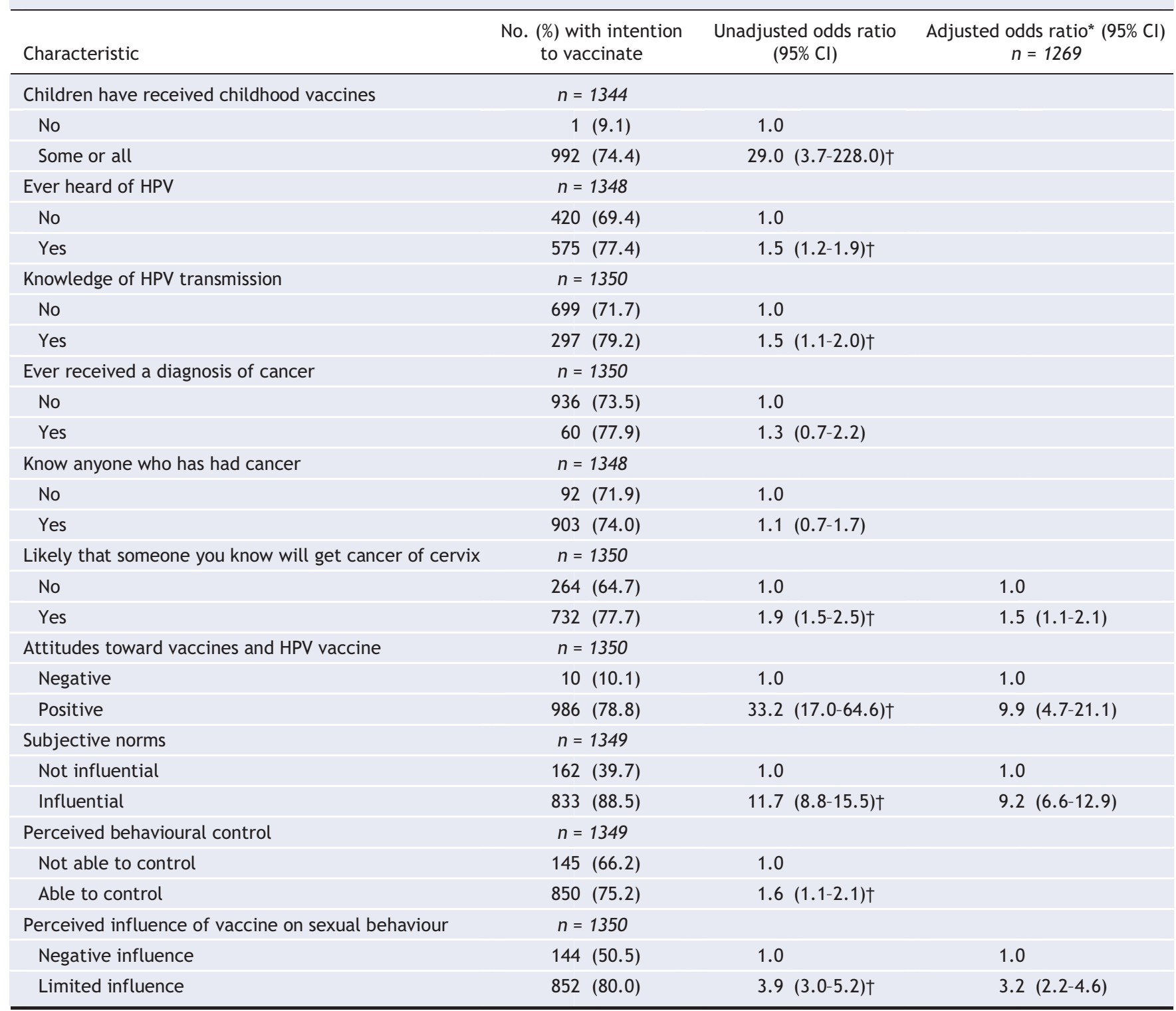

Note: $\mathrm{HPV}=$ human papillomavirus, $\mathrm{Cl}=$ confidence interval.

*Adjusted for variables that were significant in bivariate analyses and for the role of religion in daily decisions. $\uparrow p<0.05$. 
ments by the federal government ${ }^{24}$ and announcements of HPV vaccine programs by the Ontario ${ }^{25}$ and Nova Scotia ${ }^{26}$ governments underscore the need to expeditiously define key contributors to optimal HPV vaccine uptake in Canada. In this national survey, we found that the majority of responding parents would have their daughters vaccinated against HPV in the context of a publicly funded, school-based program offered in grade 6 . Specific parental characteristics were associated with the intention to not have daughters vaccinated. Health policy-makers and practitioners should ensure that planning for HPV vaccine implementation addresses these issues to ensure optimal uptake of this efficacious vaccine.

\section{This article has been peer reviewed.}

Competing interests: None declared for Monika Naus, Karen Pielak, Thomas Ehlen, Deborah Money or David Patrick. Gina Ogilvie received research grants from Merck Frosst to conduct other HPV-related studies. Valencia Remple has given several HPV-related talks and has co-chaired a series of classes and research planning workshops on HPV that were sponsered through educational grants from Merck Frosst and GlaxoSmithKline. Fawziah Marra received an honorarium and travel payment from Merck Frosst to give a talk in May 2007 at the Canadian Pharmacists Association on vaccination by pharmacists. Shelly McNeil received honoraria from Merck Frosst and GlaxoSmithKline for speaking to physician groups about HPV vaccines, and she received unrestricted grant funding from GlaxoSmithKline to conduct research about physician attitudes regarding HPV vaccines. Simon Dobson received honoraria and travel assistance from Merck Frosst and GlaxoSmithKline.

Contributors: The study was conceived by all of the authors. Study design was led by Gina Ogilvie and Valencia Remple, with assistance from the other authors. Gina Ogilvie and Valencia Remple supervised the study and conducted the data analysis. The manuscript was prepared by Gina Ogilvie with assistance from Valencia Remple. All of the authors revised the manuscript and approved the final version of the submitted publication.

Acknowledgements: Funding for the study was provided by the Public Health Agency of Canada and the BC Centre for Disease Control.

\section{REFERENCES}

I. Ault KA; Future II Study Group. Effect of prophylactic human papillomavirus LI virus-like-particle vaccine on risk of cervical intraepithelial neoplasia grade 2 , grade 3 , and adenocarcinoma in situ: a combined analysis of four randomised clinical trials. Lancet 2007;369:186I-8.

2. Paavonen J, Jenkins D, Bosch FX, et al. Efficacy of a prophylactic adjuvanted bivalent $\mathrm{LI}$ virus-like-particle vaccine against infection with human papillomavirus types 16 and 18 in young women: an interim analysis of a phase III double-blind, randomised controlled trial. Lancet 2007;369:216I-70.

3. Garnett GP, Kim JJ, French K, et al. Chapter 2r: Modelling the impact of HPV vaccines on cervical cancer and screening programmes. Vaccine 2006;24 Suppl 3: SI78-86.

4. Zimet GD, Liddon N, Rosenthal SL, et al. Chapter 24: Psychosocial aspects of vaccine acceptability. Vaccine 2006;24 Suppl 3:S2OI-9.

5. Erickson LJ, De Wals P, Farand L. An analytical framework for immunization programs in Canada. Vaccine 2005;23:2470-6.
6. Hankins M, French D, Horne R. Statistical guidelines for studies of the theory of reasoned action and the theory of planned behaviour. Psychol Health 2000;15:15I-6I.

7. Zimet GD, Perkins SM, Sturm LA, et al. Predictors of STI vaccine acceptability among parents and their adolescent children. J Adolesc Health 2005;37:179-86.

8. Zimet GD, Mays RM, Fortenberry JD. Vaccines against sexually transmitted infections: promise and problems of the magic bullets for prevention and control. Sex Transm Dis 2000;27:49-52.

9. Dempsey AF. Factors that are associated with parental acceptance of human papillomavirus vaccines: a randomized intervention study of written information about HPV. Pediatrics 2006;117:I486-93.

Io. Colgrove J. The ethics and politics of compulsory HPV vaccination. $N$ Engl J Med 2006;355:2389-9I.

II. Marlow LAV, Waller J, Wardle J. Parental attitudes to pre-pubertal HPV vaccination. Vaccine 2007;25:1945-52.

I2. Davis K, Dickman ED, Ferris D, et al. Human papillomavirus vaccine acceptability among parents of I0- to I5-year-old adolescents. J Low Genit Tract Dis 2004;8:188-94.

I3. Lazcano-Ponce E, Rivera L, Arillo-Santillan E, et al. Acceptability of a human papillomavirus (HPV) trial vaccine among mothers of adolescents in Cuernavaca, Mexico. Arch Med Res 200I;32:243-7.

I4. Lenselink CH, Gerrits MMJG, Melchers WJG, et al. Parental acceptance of human paillomavirus vaccines. Eur J Obstet Gynecol Reprod Biol DOI: Io.1oI6/j.ejogrb 2007.02.I2. Epub 2007 Mar I6 ahead of print.

I5. Kirby D, Laris BA, Rolleri L. The impact of sex and HIV education programs in schools and communities on sexual behaviors among young adults. Research Triangle Park (NC): Family Health International, YouthNet Program; 2006. Available: www.fhi.org/NR/rdonlyres/e2saa3gkcwbr422uoeyiitlrre6pd62cyh63x7rmw7xaibt ztb2zvoxpx4sb7oxmq7hugymp722f5n/KirbyFinallongreportv25I.pdf (accessed 2007 Oct I2).

I6. Monk BJ, Wiley DJ. Will widespread human papillomavirus prophylactic vaccination change sexual practices of adolescent and young adult women in America? Obstet Gynecol 2006;108:420-4

17. Population by year, by province and territory. Ottawa: Statistics Canada; modified 2006 May 29. Available: www40.statcan.ca/lor/cstor/demoo2.htm (accessed 2007 Mar 22).

I8. Stevenson CG, McArthur MA, Naus M, et al. Prevention of influenza and pneumococcal pneumonia in Canadian long-term care facilities: How are we doing? CMAJ 200I;I64:I4I3-9.

I9. Andrew MK, McNeil S, Merry H, et al. Rates of influenza vaccination in older adults and factors associated with vaccine use: a secondary analysis of the Canadian Study of Health and Aging. BMC Public Health 2004;4:36.

20. Pollack A, Saul S. Merck to halt lobbying for vaccine for girls. New York Times 2007 Feb 2I. Available: www.nytimes.com/2007/02/2I/business/2Imerck.html (accessed 2007 Oct I2).

2I. Noakes K, Yarwood J, Salisbury D. Parental response to the introduction of a vaccine against human papilloma virus. Hum Vaccin 2006;2:243-8.

22. Voigt LF, Koepsell TD, Daling JR. Characteristics of telephone survey respondents according to willingness to participate. Am J Epidemiol 2003;157:66-73.

23. Brabin L, Roberts SA, Farzaneh F, et al. Future acceptance of adolescent human papillomavirus vaccination: a survey of parental attitudes. Vaccine 2006;24:3087-94.

24. Flaherty JM. A better Canada. In: The budget plan 2007. Aspire to a strong, safer, better Canada. Ottawa: Department of Finance Canada; 2007. Available: www.budget.gc.ca/2007/bp/bpc3e.html (accessed 2007 Oct I2).

25. Human papilloma virus immunization program. Toronto: Government of Ontario, Ministry of Health and Long-Term Care; 2007 Aug 2. Available: www.health .gov.on.ca/english/media/news_releases/archives/nr_07/aug/bg_20070802.html (accessed 2007 Oct I2).

26. HPV immunization launched [news release]. Halifax: Government of Nova Scotia, Health Promotion and Protection; 2007 June 20. Available: www.gov.ns.ca/news /details.asp?id=20070620002 (accessed 2007 Oct I2).

Correspondence to: Dr. Gina S. Ogilvie, Associate Director, Division of STI/HIV Prevention and Control, BC Centre for Disease Control, 655 West I2th Ave., Vancouver BC $V_{5} Z_{4} R_{4}$; fax 604 775-o808; gina.ogilvie@bccdc.ca

For a series of articles that examine the consequences of human papillomavirus (HPV) and the efficacy of HPV vaccines, see the August 28 issue of CMAJ (available at www.cmaj.ca). A series of letters on this subject may be found on page 1524 in the current issue. 